doi: $10.5007 / 2175-795 X .2011 v 29 n 2 p 507$

\title{
Inovação pedagógica: uma resposta às demandas da sala de aula universitária
}

\author{
Carlinda Leite* \\ Preciosa Fernandes*
}

\section{Resumo}

Este texto tem como principal objetivo dar a conhecer uma experiência curricular desenvolvida em sistema b-learning com estudantes do $1^{\circ}$ ano da Licenciatura em Ciências da Educação da Faculdade de Psicologia e de Ciências da Educação da Universidade do Porto. No quadro dos desafios e dos princípios lançados pelo processo de Bolonha, o artigo problematiza possibilidades e limites do recurso aos fóruns de debate (usados no sistema b-learning) para desenvolver processos autónomos de aprendizagem. Do ponto de vista metodológico, foi utilizado um questionário de perguntas abertas que visou captar sentidos atribuídos pelos estudantes a este dispositivo pedagógico. A análise de conteúdo seguiu os procedimentos de Bardin (1991) e teve por base as ideias de Salmon (2000) quanto ao papel do professor. Globalmente, os resultados evidenciam que os estudantes apreciam muito positivamente o recurso aos fóruns de debate, considerando tratar-se de um dispositivo pedagógico importante para ampliar a sua formação. Reconhecem, ainda, que permitem uma maior acessibilidade a materiais diversos e uma melhor organizaçáo dos conteúdos constituindo, assim também, um meio de apoio ao estudo. Conclui-se que a opção por este dispositivo pedagógico converte-se num conjunto de vantagens para estudantes e professores, de entre as quais a aprendizagem autónoma ocupa posição de destaque.

Palavras-chave: B-learning. Fórum de debates. Aprendizagem.

\footnotetext{
* Doutora em Ciências da Educação pela Faculdade de Psicologia e de Ciências da Educação da Universidade do Porto (FPCE UP). Professora Catedrática da Faculdade de Psicologia e de Ciências da Educaçáo da Universidade do Porto (FPCE UP), Portugal e investigadora do Centro de Investigação e Intervenção Educativas (CIIE) da mesma Faculdade.

** Doutora em Ciências da Educação pela Faculdade de Psicologia e de Ciências da Educação da Universidade do Porto (FPCE UP). Professora Auxiliar da Faculdade de Psicologia e de Ciências da Educação da Universidade do Porto (FPCE UP), Portugal e investigadora do Centro de Investigação e Intervenção Educativas (CIIE) da mesma Faculdade.
} 


\section{Introdução}

Como o próprio título indicia, este texto pretende dar conta de um processo curricular vivido com um grupo de 65 estudantes do primeiro ano da Licenciatura em Ciências da Educaçáo da Faculdade de Psicologia e de Ciências da Educação da Universidade do Porto, em contexto de ensinoaprendizagem recorrendo à utilização dos fóruns de debate, em sistema b-learning. $\mathrm{O}$ recurso a este dispositivo implica da parte das professoras uma atenção redobrada quer ao nível do contexto presencial de sala de aula, escutando e mobilizando os estudantes para a participação no debate colectivo, quer ao nível do contexto virtual pela participação nos fóruns, desafiando-os, a partir de um tópico teórico de base, a ampliarem a reflexão "de sala de aula", através do confronto dos seus pontos de vista com o dos seus colegas e da mobilizaçáo de referentes teóricos trabalhados.

Sabendo-se que o sistema $b$-learning se caracteriza por conter processos de formação presenciais com processos de formação a distância (e-learning), é nesta última componente que se inserem os fóruns on-line a que recorremos para construirmos uma nova gramática curricular (BERNSTEIN, 1993). Por isso, no caso que aqui apresentamos, os fóruns foram usados como processo complementar às actividades de ensino-aprendizagem presenciais e com o objectivo não só de criar condiçóes para a aquisição de conhecimentos, mas também para favorecer o aprofundamento das aprendizagens dos estudantes e o desenvolvimento de competências de reflexão e de argumentação críticas sobre assuntos e situações trabalhados nas aulas presenciais.

No sentido de produzirmos uma reflexão sobre as possibilidades e os limites que este dispositivo pedagógico-didáctico oferece, apresentamos não só a reflexão que fizemos - e que decorre da análise da legislação, dos referenciais teóricos a que aderimos e do balanço dos efeitos que vão sendo gerados com a utilização dos fóruns de debate - como também as opiniōes que recolhemos dos estudantes que viveram este procedimento, através de um questionário de perguntas abertas.

O texto foi, pois, estruturado de modo a darmos conta de: princípios do Processo de Bolonha (PB); posição que temos sobre o que consideramos ser uma formaçáo orientada para o desenvolvimento de competências; possibilidades que, em nossa perspectiva, o b-learning pode oferecer para os processos de comunicação e de aprendizagem; modos como recorremos 
aos fóruns para que eles constituíssem um dispositivo potenciador de comunidades de aprendizagem e os sentidos que os estudantes lhe atribuíram. É com base nestes elementos que terminamos esta reflexão tecendo algumas consideraçôes gerais sobre possibilidades e limites que decorrem da utilização dos fóruns de debate.

\section{A declaração de Bolonha nas suas implicações para o Ensino Superior em Portugal}

O PB iniciou-se de modo informal em Maio de 1998, com a declaração de Sorbonne, e oficializou-se com a Declaração de Bolonha ${ }^{1}$ em Junho de 1999. No texto desta Declaração é expresso que

a declaraçáo da Sorbonne [...] sublinhou o papel fundamental das universidades no desenvolvimento das dimensôes culturais europeias (e) acentuou a criação do Espaço Europeu do Ensino Superior como a chave para promover a mobilidade e a empregabilidade dos cidadáos, para além do desenvolvimento geral de todo o continente. (DECLARAÇÁO DE BOLONHA, 1999, p. 1).

Para a concretização deste processo, foram tomadas, entre outras, as seguintes medidas:

Adopçáo de um sistema de graus de acessível leitura e comparaçáo, também pela implementação do Suplemento ao Diploma.

Adopçáo de um sistema essencialmente baseado em dois ciclos principais, o graduado e o pós-graduado. - Estabelecimento de um sistema de créditos - [...] sistema ECTS - como um correcto meio para promover a mobilidade mais alargada dos estudantes. Promoção da cooperação europeia na avaliaçấo da qualidade, com vista a desenvolver critérios e metodologias comparáveis.

Promoção das necessárias dimensões europeias do Ensino Superior, especialmente no que respeita ao desenvolvimento curricular, à cooperação 
interinstitucional, aos esquemas da mobilidade e aos programas integrados de estudo, de formação e de investigação. (DECLARAÇÃO BOLONHA, 1999, p. 2).

A par destas medidas, foi enunciada a intenção de guardar "um completo respeito pela diversidade de culturas, línguas, sistemas nacionais de educaçáo e da autonomia universitária - para consolidar o espaço europeu do Ensino Superior" (DECLARAÇÃO BOLONHA, 1999, p. 2). Sendo este espaço perspectivado no sentido de favorecer a mobilidade de discentes e de docentes e a empregabilidade de diplomados dentro deste espaço europeu, foi também atribuído ao processo o desejo de permitir que os graus conferidos pelas Universidades europeias sejam "facilmente legíveis e comparáveis" (DECLARAÇÃO BOLONHA, 1999, p. 2). ${ }^{2}$

A ideia base assenta na criaçáo de um Espaço Europeu de Ensino Superior (EEES) que permita a qualquer estudante do ensino superior iniciar a sua formação académica numa determinada instituição europeia, concluir a sua formação superior e obter um diploma que é reconhecido em qualquer universidade de qualquer Estado-membro. Isto pressupôs que as instituições de ensino superior europeias se organizassem no sentido de poderem funcionar de modo articulado e regido por processos de formação de base similar e com graus académicos homogeneizados e reconhecidos entre si de modo a poderem atribuir diplomas equivalentes.

Destas medidas, a organização dos cursos em função de European credit transfer System (ECTS), isto é de um novo sistema de créditos curriculares constitui um dos "instrumentos mais relevantes desta política europeia de evolução do paradigma formativo" (decreto-lei no 42/2005 de 22 de Fevereiro, preâmbulo) e, nesse sentido, exige, nesta nossa reflexão, uma clarificação das ideias que a suportam. A publicação, em Portugal, deste decreto lei (PORTUGAL, 2005) preconizou para o Ensino Superior:

uma importante mudança nos paradigmas de formação, centrando-a na globalidade da actividade e nas competências que os jovens devem adquirir, e projectando-a para várias etapas da vida de adulto, em necessária ligaçáo com a evolução do conhecimento e dos interesses individuais e colectivos. ${ }^{3}$ 
Essa concepção de formação, e recorrendo ainda ao diploma legal que aqui temos por referência, assenta fundamentalmente nos seguintes aspectos:

a) O reconhecimento da necessária adaptação do processo de aprendizagem aos conceitos e perspectivas da sociedade moderna e aos meios tecnológicos disponíveis.

b) A percepção da necessidade de tornar o ensino superior mais atractivo e mais próximo dos interesses da sociedade, permitindo aos jovens uma escolha que lhes traga maior satisfação pessoal e maior capacidade competitiva no mercado europeu.

c) A percepção de que o conhecimento é um bem universal, na abertura que se preconiza deste espaço do conhecimento a países terceiros (PORTUGAL, 2005).

Esta concepção de formação coloca, pois, a centralidade na figura do estudante atribuindo-lhe um papel de destaque

quer na organização das unidades curriculares,
cujas horas de contacto assumirão a diversidade de
formas e metodologias de ensino mais adequadas,
quer na avaliaçáo e creditação, as quais considerarão
a globalidade do trabalho de formaçáo do aluno,
incluindo as horas de contacto, as horas de projecto,
as horas de trabalho de campo, o estudo individual
e as actividades relacionadas com avaliaçáa, abrindo-
se também a actividades complementares com
comprovado valor formativo artístico, sócio-cultural
ou desportivo. (PORTUGAL, 2005).

Na sequência desta legislação, e dos objectivos do Processo de Bolonha, em 2006, o decreto-lei no 74/2006, de 24 de Março (PORTUGAL, 2006), no quadro do Programa do XVII Governo Português, reafirma esta política europeia para o ensino superior, explicitando mais claramente os objectivos que orientam este $\mathrm{PB}$ e fazendo uma caracterização mais detalhada de cada um dos três ciclos de estudos previstos para o ensino superior. Nesta caracterizaçáo é dada continuidade à diferenciaçáo de objectivos entre os subsistemas politécnico e universitário, tal como já acontecia antes, enunciando-se, agora, que têm "igual dignidade e exigência mas de vocaçôes diferentes”. De igual modo, são definidos os:

PERSPECTIVA, Florianópolis, v. 29, n. 2, 507-533, jul./dez. 2011

http://www.perspectiva.ufsc.br 


\begin{abstract}
objectivos de cada um dos ciclos de estudos na perspectiva das competências a adquirir, adoptando os resultados do trabalho colectivo realizado a nível europeu e concretizado nos descritores de Dublin, tendo presente que a transição de um sistema de ensino baseado na transmissão de conhecimentos para um sistema baseado no desenvolvimento de competências pelos próprios alunos é uma questâo crítica central em toda a Europa, com particular expressão em Portugal. (PORTUGAL, 2006).
\end{abstract}

Sendo a concepção de formação essencial para a compreensão das razóes e dos procedimentos a que recorremos nos fóruns de debate, aqui em análise, realçamos o que é expresso a este propósito neste diploma legal. Apontando a necessidade da formação ser adequada ao novo modelo de organização do ensino superior, é referido neste decreto-lei no 74/2006 que este processo de adequação se concretiza através da:

a) passagem de um ensino baseado na transmissão de conhecimentos para um ensino baseado no desenvolvimento de competências;

b) orientação da formação ministrada para os objectivos específicos que devem ser assegurados pelos ciclos de estudos do subsistema, universitário ou politécnico, em que se insere;

c) determinação do trabalho que o estudante deve desenvolver em cada unidade curricular - incluindo, designadamente, quando aplicáveis, as sessōes de ensino de natureza colectiva, as sessōes de orientação pessoal de tipo tutorial, os estágios, os projectos, os trabalhos no terreno, o estudo e a avaliação - e sua expressão em créditos de acordo com o sistema europeu de transferência e acumulação de créditos (ECTS: European Credit Transfer and Accumulation System) (PORTUGAL, 2006).

De entre estas adequaçóes que são previstas, situamos aqui a que se prende com a mudança dos processos de ensino-aprendizagem. Deste ponto de vista, o recurso ao b-learning, e de modo particular a utilizaçáo de fóruns de debate - objecto de atenção na análise que aqui estamos a realizar - representa um dispositivo de inovação pedagógica que consideramos adequado aos princípios inerentes ao $\mathrm{PB}$ e aos desafios que coloca ao exercício da profissionalidade docente no ensino superior. 


\section{A formação orientada para o desenvolvimento de competências como uma nova gramática curricular}

Como já fizemos referência, nesta reflexão sobre o $\mathrm{PB}$, um aspecto que não pode ser descurado relaciona-se com o paradigma da formação. Também como sustentámos, os discursos produzidos têm aludido no sentido da formação se organizar não na lógica da mera aquisição de conhecimentos, no quadro de um paradigma transmissivo, mas sim segundo um paradigma activo onde professor e estudantes tenham protagonismo.

É no quadro destes argumentos que entendemos a referência, nos documentos emanados do $\mathrm{PB}$, à importância de uma formação orientada para o desenvolvimento de competências. Esclarecemos que, para nós, associamos a competência a algo que é específico ao próprio indivíduo, ou, como em outro momento afirmámos (LEITE, 2006) aos seus "saberes tácitos", à sua capacidade para desenvolver a inteligência no agir em situaçôes que jamais são iguais e estáveis. Por isso, quando se afirma pretender que os diplomados e diplomadas com cursos universitários sejam profissionalmente competentes, entendemos esta intenção no sentido de criar condições de formação que permitam adquirir capacidade para agir inteligentemente nas situaçôes reais, ou seja, que se recorra a processos de formação que coloquem a ênfase nas acçóes dos estudantes e nas suas aprendizagens. A este propósito, Meirieu (1988, p. 75), baseando-se no que designa por "uma filosofia do aluno como sujeito, uma pedagogia da autonomia como capacidade de pilotar sozinho, progressivamente, as suas próprias aprendizagens", propóe o recurso a processos pedagógicos que envolvem os estudantes na contextualização, descontextualização e recontextualização dos saberes. Este também foi um dos princípios que tivemos por referência quando recorremos aos fóruns de debate a que nesta comunicação nos referimos.

Tornando claro o conceito de formação que nos orienta, frisamos que não ignoramos os conhecimentos, não tendo, no entanto, como finalidade última a sua aquisição, pois a mira é desenvolver competências imprescindíveis à intervenção. Temos também a esclarecer que, neste entendimento, não associamos competência ao "desempenho", conceito que acompanhou as teorias curriculares e de educação dos paradigmas tecnicistas.

Ao contrário, o conceito que orienta a nossa posição, e tal como em outros momentos sustentámos (LEITE, 2006), decorre de considerarmos 
que a organização do currículo e os processos do seu desenvolvimento em função de competências têm como intenção dar sentido social ao que se selecciona para ser ensinado e ao que se aprende e, por isso, estabelecer uma forte relação do saber escolar formal com as questôes sociais.

Em síntese, o entendimento que seguimos aproxima-se da visão de Lessard (2006, p. 233-234) quando afirma que:

Desenvolver competências não é tanto aprender comportamentos precisos e específicos - por assim dizer, extirpados tanto da experiência e da trajectória do sujeito como da situação e, assim objectivados e essencializados - ... mas antes mobilizar e combinar um conjunto de recursos cognitivos e não-cognitivos para levar em conta a complexidade da situaçáo educativa e nela agir de modo finalizado, adaptado e 'eficaz'.

Neste sentido, a competência náo é sinónimo de desempenho e o seu desenvolvimento está, tal como Wittorski (2004, p. 88) afirma, associado "às noções da organização formadora que qualifica e ensina". Reconhecendo ser um velho desafio fazer com que a formação mantenha maior relação com as situaçôes sociais e do quotidiano, o debate ${ }^{4} \mathrm{em}$ torno dos compromissos de Bolonha tem gerado algum enfoque na necessidade de se repensar as competências desejadas no final dessa formação e de, em torno delas, delinear os planos curriculares e os programas das disciplinas que os configuram. Dito de outro modo, o debate tem realçado a importância do recurso a metodologias inspiradoras de processos de ensino-aprendizagem potenciadores do desenvolvimento de competências interpessoais, no contexto de uma maior transparência dos conteúdos e no recurso a processos de tutoria e de envolvimento efectivo dos actores nesse processo de ensinar e de aprender. É no quadro destas ideias, e em nossa perspectiva, que, reafirmamos, se situam as possibilidades geradas pela utilização dos fóruns de debate nos processos de desenvolvimento do currículo neste curso de Ciências da Educação (CE).

Orienta-nos, pois, a crença pedagógica de que os fóruns de debate criem condiçóes para que os estudantes concretizem aprendizagens comprometidas e modos de autoformaçáo apoiados por processos de diálogo e de tutoria, entendida como meio potenciador de um acompanhamento dialogante. 


\section{O b-learning como processo de construção de novas possibilidades de comunicação e de aprendizagem}

Como já referimos na introdução a este texto, a principal intenção que lhe subjaz reporta-se à importância de aqui darmos conta de uma experiência formativa desenvolvida na modalidade b-learning no âmbito de uma unidade curricular da Licenciatura em Ciências da Educação, da Universidade do Porto. Também como em pontos anteriores sustentámos, a opção por esta modalidade educacional decorre de razóes diversas. Desde logo pela fácil acessibilidade às novas tecnologias que permitem, em simultâneo, um diálogo de muitos com muitos, em vez de um para muitos, isto é, permitir estabelecer uma comunicação e um diálogo com todo/as os/as estudantes de um mesmo grupo/turma, promovendo interacçóes colectivas. $\mathrm{Na}$ base desta opção está também o facto de acreditarmos que esta é mais uma possibilidade para mobilizar os estudantes a "aprender a aprender", tendo em conta a perspectiva construtivista de aprendizagem que nos orienta. A modalidade b-learning é por nós considerada uma inovação pedagógica interessante do ponto de vista da configuraçấo de uma nova gramática curricular (BERNSTEIN, 1993) na medida em que a perspectivamos como estratégia complementar aos processos presenciais de sala de aula.

Tal como o termo indica, o b-learning corresponde a um modelo de formação misto em que uma parte da aprendizagem se faz através da internet, no sistema de e-learning, e outras actividades são desenvolvidas em contexto de sala de aula (sessóes de contacto/presenciais). Morais e Cabrita (2008, p. 160) defendem que o recurso a valências de e-learning "poderá contribuir para a transformação dos actuais cenários educativos, facilitando a construção de comunidades online e permitindo a integração do presencial e do virtual na construção de novos contextos de aprendizagem". E, nessa base, consideram ainda que o recurso ao b-learning "em ambientes de formaçáo poderá ser encarado como uma das estratégias potenciadoras de uma participação mais activa e autónoma do (estudante) na construção das suas aprendizagens" (MORAIS; CABRITA, 2008, p. 160). Neste sentido, a utilização destes cenários virtuais de aprendizagem constitui uma mais-valia, sobretudo se tivermos em conta que o seu grande objectivo é permitir não só o acesso a conteúdos mas, principalmente, facilitar a interacção e promover a aprendizagem colaborativa. No entanto, como sustenta Dias (2008, p. 2), o 
"próprio conceito de educação em rede só atinge o seu verdadeiro potencial quando este se encontra ao serviço da construção da aprendizagem como um processo de criação e inovação realizado colaborativamente".

Este trabalho colaborativo exige por parte dos intervenientes, professores e estudantes, uma postura de compromisso na participação das propostas educacionais para que estas não fiquem votadas ao insucesso. $\mathrm{Ou}$ seja, como advertem Morais e Cabrita (2008, p. 161), "o recurso a ambientes virtuais de aprendizagem, assentes em pressupostos de interacçáo e de aprendizagem colaborativa, exige, naturalmente, novas competências e novas posturas de professores e (estudantes) perante o ensino e a aprendizagem".

A advertência destes autores coloca centralidade no papel do/a professor/a no sentido de manter um nível de entusiasmo positivo no grupo de estudantes. Espera-se, pois, do professor uma responsabilidade que vai para além da instrução, isto é, da mera transmissão de informaçóes e de conhecimentos, e se alarga a um trabalho de escuta, de animaçáo e de diálogo facilitador da aprendizagem. A este propósito vale a pena convocar Lévy (1997, p. 184 apud MORAIS; CABRITA, 2008, p. 170) quando define esta conduta pedagógica:

O docente torna-se um animador da inteligência colectiva dos grupos de que se encarrega. A sua actividade centrar-se-á no acompanhamento e na gestão das aprendizagens: a incitaçáo à troca dos saberes $[\ldots]$ e a pilotagem personalizada dos trajectos da aprendizagem, etc.

Esta visão do papel do professor, no quadro de um modelo misto de ensino-aprendizagem, ou seja do b-learning, evoca, de facto, uma pedagogia assente em processos interactivos que induzem novas possibilidades de comunicação e de aprendizagem. No quadro desta perspectiva são igualmente valorizados os papéis dos estudantes e dos professores/tutores, assumindo estes últimos, como já referimos, uma postura de permanente encorajamento e de manutenção de entusiasmo do grupo. Reconhecendo, portanto, ser este um meio potenciador de aprendizagens mais significativas, porque é assente em processos de contratualização e de co-responsabilização, enganemo-nos se considerarmos ser um processo de fácil operacionalização e gestấo. Dito de outro modo, embora acreditemos nas potencialidades 
deste modelo de formaçáo b-learning, náo podemos deixar de considerar que ele exige bem mais do professor, e também dos estudantes, do que um convencional modelo de ensino, confinado apenas à sala de aula e aos desígnios e regras do professor. Talvez seja esse carácter de exigência que faz desviar muitos professores de processos deste tipo. Ao mesmo tempo reconhecemos também que as condiçóes e o volume de trabalho do professor do ensino superior universitário e as componentes de investigação e de docência a que igualmente tem de responder não se compadecem com este tipo de experiências pedagógicas, ficando estas remetidas a experiências individuais e de carácter pontual.

Apesar disso, consideramos, em síntese, que o modelo de formação b-learning, inspirado por uma visão de aprendizagem activa e autónoma, configura uma nova possibilidade de comunicação educacional, instituindose, assim, em estreita proximidade com o espírito de Bolonha, razão talvez pela qual o recurso a estratégias baseadas no e-learning, particularmente o recurso às plataformas (moodle e outras), se tem vindo a intensificar no ensino superior em Portugal, após a implementação do processo de Bolonha.

\section{O recurso aos fóruns como dispositivo potenciador de comunidades de aprendizagem: uma reflexão a partir de uma experiência em CE}

Das ideias até ao momento explicitadas, pensamos ter tornado claro que, em nossa perspetiva, o sistema de formação b-learning constitui um meio para a construção de novas possibilidades de comunicação e de aprendizagem. Neste sentido, o trabalho que nestes três últimos anos temos vindo a desenvolver com os estudantes da Licenciatura em Ciências da Educação da FPCE UP, numa unidade curricular do $2^{\circ}$ ano, tem constituído para nós um meio de grande aprendizagem neste domínio e, ao mesmo tempo também, tem sido uma fonte de inspiração, não só no que respeita à manutenção e enriquecimento desta experiência, como também ao aprofundamento teórico do sentido pedagógico que assume para todos, professoras e estudantes. Nesta atitude pedagógica, posicionamo-nos em proximidade com os que sustentam que um dos principais efeitos destes processos de aprendizagem on-line é a criação de comunidades de aprendizagem (TORRES, 2001; COLL, 2003; DIAS, 2008; MORAN, 2010). 
A expressão comunidade de aprendizagem abarca diferentes significados, sendo, segundo Coll (2003), difícil identificar experiências que possam ser descritas, enquanto tal, de forma coerente e objectiva. ${ }^{5}$ De entre os tipos de comunidades de aprendizagem descritos pelo autor, a experiência que aqui apresentamos insere-se nas características de uma comunidade virtual de aprendizagem $^{6}$ (COLL, 2003). A ideia que apoia este tipo de comunidade é a de que esta "possibilite uma fácil integração e que seja formada por instâncias ou pessoas que estão conectadas em rede e que têm como foco um conteúdo de aprendizagem" (COLL, 2003). Em complementaridade com esta visão, Moran (2010) considera que a construçáo de comunidades em ambientes virtuais constitui "uma forma flexível para criar vínculos, manter a motivação e atender a diferentes estilos de aprendizagem". Deste modo, a

Comunidade desenvolve-se não só na partilha de interesses, o que corresponde à sua forma mais simples, mas também através da integração da diversidade de representaçóes, incluindo a voz social, como refere Wenger (2007), na construção das práticas comuns de participação, interacção e aprendizagem colaborativa. (DIAS, 2008, p. 6).

No âmbito da experiência, b-learning, que aqui partilhamos, o recurso aos fóruns semanais tem-se revelado uma valência pedagógica de suprema importância. Tal importância resulta, em primeiro lugar, do papel que os fóruns assumem na construção de um sentido mais democrático de partilha e de construção de saberes, através da construção individual e colectiva de narrativas. Na linha de pensamento de Dias (2008, p. 6), subjacente a esta prática está um sentido de "liderança partilhada, o qual corresponde a um exercício de autonomia da comunidade orientado para a negociação colaborativa do sentido na construção das aprendizagens". Em segundo lugar, resulta da função que consideramos que os fóruns desempenham no apoio ao estudo e à mobilização e construção de um pensamento mais reflexivo sobre os assuntos/matérias trabalhados/as em contexto presencial de sala de aula.

No que respeita a estes aspectos, importa salientar o nosso papel, por um lado, enquanto moderadoras das participaçóes dos estudantes no sentido de criar um clima de entusiasmo e de confiança que facilite a participação colectiva e a partilha de reflexóes e de saberes, tal como atrás ressaltámos, e, por outro, enquanto supervisoras de um processo que se deseja, por todos, 
participado e enriquecido, incutindo um espírito de incentivo e também de rigor científico.

Este nosso procedimento de moderação pedagógica e de gestão aproxima-se do conceito de e-moderador, sustentado por Dias (2008, p. 5) quando refere que:

o papel do e-moderador nos ambientes de aprendizagem on-line desenvolve-se, fundamentalmente, através do processo de construção de significados em detrimento dos procedimentos associados à transmissáo de conteúdos, tendo como referência uma abordagem construtivista da educaçáo.

Com efeito, ancorando-nos numa perspectiva construtivista de aprendizagem, que pressupóe criar ambientes indutores do "aprender a aprender", a cedência aos estudantes de espaço e voz para aprendizagens autónomas não significa uma demissão de um trabalho de moderação pedagógica e de gestão que permita acompanhar, nos fóruns, o processo de aprendizagem e que estimule participaçóes sustentadas e reflectidas. Nestes processos de aprendizagem b-learning, em termos pedagógicos, o professor $^{7}$ age como facilitador da aprendizagem, recorrendo a estratégias capazes de promover a discussão do grupo em torno de conceitos essenciais para a disciplina ou para o curso. Cumprindo funçóes na área social, o professor deverá procurar estimular as relaçóes pessoais entre os elementos do grupo para que estes se sintam à vontade na partilha das suas opiniōes dentro da comunidade de aprendizagem (MORAIS; CABRITA, 2008). No que respeita à área de gestão, mais relacionada com as questôes organizacionais e de administraçáo da unidade curricular, o professor estabelece objectivos e define as regras de participação, por exemplo.

Da experiência que desenvolvemos, e cujos sentidos atribuídos pelos estudantes daremos conta no ponto seguinte, os fóruns de debate constituem uma excelente oportunidade para que a aprendizagem se faça em ambientes de forte implicaçáo e de envolvimento dos estudantes. Todavia, para que tal aconteça haverá, como salientámos, a necessidade de os professores também se envolverem de forma contínua, acompanhando e moderando o desenrolar da actividade, de modo a não só garantir uma participação alargada dos estudantes como também a de cunhar o processo de cientificidade e rigor. 
$\mathrm{Na}$ situação concreta em que vivemos, essa foi uma intenção que nos acompanhou ao longo de toda a experiência. $\mathrm{Na}$ estratégia adoptada nos fóruns, seguimos de perto as ideias de Salmon (2000) quanto ao papel do professor. Segundo este autor, a intervençáo do professor na construção e desenvolvimento de processos on-line deve passar por cinco etapas: a primeira diz respeito ao acesso e motivaçâo dos alunos, sendo este um momento ao qual o professor deve prestar especial atenção, pois dele dependerá o sucesso futuro da experiência. Para além de criar um bom ambiente de recepção, deve explicar os objectivos e todos os procedimentos de acesso e de utilização e estimular a participação através de actividades estimulantes; a segunda etapa é designada de socialização on-line. Trata-se de uma etapa de encontro entre os participantes, a partir da qual se começa a germinar uma comunidade de aprendizagem, isto é, se inicia o processo de construção de identidades on-line, pela interacção que se enceta com os demais participantes. $\mathrm{Na}$ experiência por nós vivida esta foi uma etapa que foi ganhando maior nitidez à medida que se foi instituindo um clima de maior confiança entre todos e se foi expressando um sentimento de empatia e de cumplicidade entre o grupo-turma; a terceira etapa é definida como a partilha de informação. Havendo já uma socialização on-line, é importante que os estudantes conheçam as regras de funcionamento de base à partilha de informação para que as reflexôes e a construção de conhecimento colectivo, através dos fóruns, se faça de forma sustentada e rigorosa. Para isso, o professor deve planificar atempadamente os fóruns que têm como intenção a partilha de informação no sentido de que todos os estudantes conheçam de modo muito claro qual a estratégia e o seu objectivo. Esta foi uma etapa à qual demos também grande importância não só no que diz respeito à calendarização e à definição do tópico de debate presente nos fóruns, no quadro geral do plano das aulas, como também na manutenção de um espírito positivo de participação e de estabelecimento de pontos de situação com os estudantes relativamente ao nível e qualidade das participaçôes; a etapa de construção de conhecimento. Esta etapa é caracterizada por uma participação em que os estudantes procuram, num registo colaborativo, construir conhecimento. Nos fóruns que realizámos, esta ideia foi traduzida na sugestão de que os estudantes tinham de sustentar teoricamente as suas posiçôes e de incorporar nas suas reflexóes os pontos de vista dos colegas. O papel do professor é fundamental nesta 
etapa, devolvendo feedback quanto à forma e ao modo de construção do conhecimento, colocando atenção, por exemplo, na relação das reflexões com os conteúdos trabalhados e no rigor e cientificidade da escrita. Para além disso, o professor deve também construir sínteses do conhecimento produzido nos fóruns e devolvê-las aos estudantes no sentido de lhes fornecer pistas para o trabalho futuro; a quinta etapa corresponde ao que o autor designa de desenvolvimento. Trata-se da fase em que os estudantes demonstram já criatividade e autonomia na procura de novos elementos e informaçóes que possam enriquecer a sua aprendizagem.

Em síntese, este quadro de referência foi por nós mobilizado não só como contributo para delinearmos modos de acção que desenvolvemos, enquanto professoras, moderadoras e gestoras de formação, como também para compreendermos o modo como se desenrolaram os fóruns on-line, do ponto de vista da participação dos estudantes. É essa intenção que está na base das ideias que apresentamos no ponto seguinte deste texto, e onde damos conta das vozes dos estudantes que sobre o assunto inquirimos.

\section{Um balanço do recurso aos fóruns feito a partir das vozes dos estudantes}

Sendo nosso desejo cruzar as nossas opiniōes, de professoras, com as dos estudantes que viveram, nos processos de desenvolvimento do currículo, situaçóes de participação em fóruns on-line, propusemos que respondessem a um pequeno questionário, anónimo e de perguntas abertas. Os discursos produzidos foram depois por nós trabalhados recorrendo à técnica de análise de conteúdo (BARDIN, 1991; VALA, 1986). Essa análise seguiu, nos aspectos que aqui apresentamos, a regra de categorias predefinidas e que correspondem às etapas a que alude Salmon (2000) e que atrás caracterizámos. Assim, tendo por referência essas categorias, a análise realizada aos discursos dos estudantes ${ }^{8}$ da licenciatura em Ciências da Educaçáo permitiu situar sentidos que atribuem aos fóruns on-line, e que passamos a explicitar:

\section{a) Acesso e motivação dos alunos}

Do ponto de vista dos estudantes, o recurso aos fóruns on-line permitiu uma melhor organização da informação e facilidades de acesso aos materiais 
trabalhados nas aulas e a outros considerados importantes para ampliar a formaçáo. A este propósito é dito, por exemplo, que este recurso:

Permite, a qualquer hora do dia, e em nossa casa, ter acesso a materiais importantes para a nossa formação académica [...] e estar sempre a par das temáticas abordadas.

Permite um acesso fácil e cómodo aos materiais de formação.

Constitui um bom meio para colocar questöes e dúvidas para as quais sabemos que existem respostas.

Os discursos dos estudantes deixam também transparecer sentidos que focam a pertinência do uso deste recurso na captação do seu interesse para as matérias a aprender, tal como é evidente pelas frases:

Foi uma forma de me estimular para determinados assuntos/conteúdos para os quais não estava muito motivada.

Para além de permitir ampliar as minhas competências informáticas, constitui um procedimento que considero muito estimulante para uma aprendizagem activa e significativa.

Salientam-se, ainda, ideias que expressam o sentido de democraticidade a que parece ser associado o uso deste processo pedagógico-didáctico:

É bastante importante para trabalhadores-estudantes que nem sempre podem acompanhar convenientemente as aulas presenciais.

Permite que todos, estudantes a tempo inteiro e estudantes-trabalhadores, tenham palavra na construção de conhecimento.

De modo geral, e em síntese, os estudantes focam a importância da metodologia b-learning como uma oportunidade para desenvolver competências no domínio das Novas Tecnologias, por eles consideradas essenciais para uma vida profissional futura.

\section{b) Socialização on-line}

No que se refere a este aspecto, os discursos dos estudantes são ilustrativos da ideia de que o processo vivido permitiu um efeito maior de socialização com o grupo-turma e com as professoras. Esta socialização, do ponto de vista de alguns estudantes, aconteceu pelo facto dos fóruns terem 
permitido um nível de comunicação, de partilha de ideias e de saberes, não alcançável num contexto presencial. Esta ideia está presente nos seguintes registos:

Os fóruns permitiram-me uma exposição perante o grupo-turma e as docentes e uma troca de pontos de vista em relação aos temas em debate que nunca conseguiria, pela minha timidez, em contexto de sala de aula.

Os fóruns constituíram um espaço de informação, tornada acessivel a todos, e sobre a qual todos fomos capazes, mais cedo ou mais tarde, de ir emitindo uma opiniáo própria.

Através estes fóruns fomos capazes de mostrar aquilo que por vezes não conseguimos demonstrar em aula.

Ajudaram-me a desenvolver uma melhor comunicação com o grupo-turma e com as docentes.

Permitiram-me ampliar a minha capacidade de partilhar os meus conhecimentos e de os confrontar com os pontos de vista dos meus colegas,... o que não é fácil.

Foram uma oportunidade de interagir com os meus colegas, ficando a conhecê-los melhor, e de me enriquecer em todos os aspectos.

Como se depreende dos discursos dos estudantes, os fóruns parecem ser vistos como um meio privilegiado de melhorar não só as competências individuais de comunicaçáo, na medida em que aumentam a capacidade de emitir uma opinião e de a partilhar com a turma, como também parece terem configurado um espaço optimizador das relaçóes entre os estudantes e entre estes e as professoras.

\section{c) Partilha de informação}

Esta é uma dimensão muito valorizada por todos os/as estudantes, sendo vários os argumentos apresentados. Para uns, os fóruns constituem um meio de se manterem informados e de acompanharem os assuntos abordados nas aulas, para outros são uma fonte de enriquecimento da formação na medida em que, para além de permitirem um mais fácil acesso à informação disponível, representam oportunidades de mobilização de diferentes fontes de saber. Para outros, ainda, são meios de partilha e de debate de ideias. Como referem alguns estudantes: 
Os fóruns permitiram-me acompanhar a matéria dada nas aulas de um modo interessante: através da emissão de um pensamento próprio sobre um assunto e da sua partilha aos restantes colegas.

Estes fóruns são uma possibilidade de cada estudante expressar as suas ideias... é um meio de dar a palavra a todos e de todos se pronunciarem sobre um mesmo assunto.

Existem sempre pontos concordantes e discordantes, mas o importante é aprendermos uns com os outros, mediante as leituras que fazemos, e que vão para além dos materiais indicados pelas docentes, e a interpretaçâo que cada um faz do assunto.

A mobilização da informação possibilitada pelos fóruns de debate é também vista por outros/as estudantes como uma possibilidade de debate de ideias que permite "ampliar horizontes" e aprender colectivamente, tal como é expresso nos seguintes registos:

São um excelente meio de partilha de informação e de confronto de pontos de vista... onde o debate acontece, permitindo-nos reflectir acerca das nossas opinióes e da dos colegas e compreender a multiplicidade de pontos de vista com os quais podemos aprender imenso.

Este método contribui para o desenvolvimento de competências transversais e alargar os "nossos horizontes" através da emissão de um pensamento pessoal $e$ das partilhas que se estabelecem entre todos [...] a partir de determinado momento senti-me mais integrada no grupo.

Ao participar neste tipo de fóruns somos confrontadas com questóes pertinentes e inteiramente ligadas aos conteúdos do programa, sendo que neste âmbito temos a possibilidade de partilhar, confrontar e questionar com toda a comunidade de estudantes e com as docentes.

o facto de todos partilharem o seu ponto de vista e de o termos de incorporar na construção da nossa reflexão, mobilizando também os referenciais teóricos de base à unidade curricular, leva a que desenvolvamos não só o espírito crítico, como também a competência de sabermos construir reflexôes devidamente fundamentadas; 
$\mathrm{Na}$ verdade, através dos fóruns podemos partilhar informaçôes, discutir conceitos e conteúdos, dar a nossa opiniáo, num grupo que considerávamos ser "nosso", isto porque sabíamos quem estava "do lado de lá", com quem estávamos a partilhar, a problematizar, a tirar dúvidas, a trocar saberes [...] sentia fazer parte de uma "turma-on-line.

Como se pode depreender destes discursos, os fóruns on-line parecem também ter contribuído para o desenvolvimento de um sentido de pertença ao grupo, configurador do que tem vindo a ser designado por comunidade virtual de aprendizagem (COLL, 2003) e ilustrado na ideia de "turma on-line".

\section{d) Construção de conhecimento}

Dos registos analisados, a construçáo de conhecimento é referenciada por muitos/as estudantes como sendo um ganho obtido com a participação nos fóruns. Os focos evidenciados, representativos da construçáo desse conhecimento, são também variados, como se pode constatar dos depoimentos seguintes:

Estes fóruns semanais, para além de criarem hábitos de estudo e de organização da informação, possibilitam a expressão de ideias, dúvidas e pensamentos e a construçáo colectiva de novos conhecimentos, a partir de uma ideia-base.

São um óptimo meio de difusão de conteúdos e de aprendizagem conjuntas.

Os fóruns têm permitido uma melhor integração da unidade curricular com outros saberes disciplinares.

As participaçôes que tive nos diferentes fóruns em torno de diferentes tópicos foram um excelente meio de auto e hetero-formação, pois todos contribuimos para que todos aprendessem.

Através destes fóruns aprendemos maneira diferente sobre temas ou conteúdos propostos ... diria mesmo que fizemos aprendizagens autónomas...

A partir de um tópico, construímos ideias que são por todos partilhadas e que na versão final configuram um conhecimento que é de todos. 
A construçáo colectiva de conhecimento e a aprendizagem autónoma ressaltam como dimensóes centrais nos discursos dos estudantes reforçando, assim, a ideia de os fóruns configuraram a emergência de uma comunidade de aprendizagem. O depoimento seguinte parece ser bem expressivo deste pensamento:

\begin{abstract}
Num sistema de ensino que se pauta por uma lógica individualista e competitiva, este meio pedagógico que implica todos na discussão e na construção colectiva de uma reflexão, constituiu uma boa oportunidade de aprendizagem e de aprofundamento dos conhecimentos desta unidade curricular.
\end{abstract}

De salientar ainda argumentos que colocam a tónica nas possibilidades abertas pelos fóruns na formação global dos estudantes, não os confinando, assim, à componente cognitiva da aprendizagem e reforçando dimensóes como a ética, o respeito pelo outro, as atitudes e valores:

O confronto de ideias permitiu-me ampliar os meus conhecimentos, desenvolver a capacidade argumentativa e o crescimento como um ser reflexivo.

A minha participação nos fóruns permitiu que eu crescesse enquanto pessoa, sabendo respeitar as opinióes dos meus colegas e entendendo-as como uma mais valia para a minha formação.

A exposição a que estávamos sujeitas nas participaçóes foi bem conduzida pelas docentes e houve sempre um respeito de todos pelos opinióes que cada um dava.

Só com um clima de grande confiança que se estabeleceu entre todos, estudantes e docentes, é que foi possivel alcançar um nivel de participação tão bom e em que todos se sentiram incluidos e com voz activa.

Deste conjunto de depoimentos sobressai como ideia síntese a que evidencia os fóruns on-line não apenas como meios técnico-pedagógicos, ao serviço do desenvolvimento do currículo, mas também como dispositivos formativos potenciadores de desenvolvimento de competências globais.

\title{
e) Desenvolvimento
}

Em relação a esta etapa a que se refere Salmon (2000), os discursos analisados revelam menos evidências. Contudo, e na linha de alguns 
depoimentos já enunciados, constata-se por parte de alguns/mas estudantes uma consciência pedagógica reveladora da importância do uso deste recurso. Como bem expressa uma estudante:

Sem a participação activa das docentes, os estudantes foram criando o seu próprio estilo de reflexão e de participação que, em minha opinião traduz o verdadeiro sentido de uma comunidade de aprendizagem.

A minha atitude e o modo de olhar para a formação já não são iguais... e tenho a certeza de que esta mudança se deve à minha participação nos fóruns.

Sou hoje mais capaz de procurar autonomamente respostas/informação para as questôes com que for confrontando.

Com efeito, apesar da aparente ausência de evidências, estes registros parecem revelar que muitos estudantes estarão agora mais capazes de participar autonomamente na construção das suas aprendizagens e de ser mais criativos e responsáveis.

\section{Considerações finais}

Pelas ideias teóricas que ao longo do texto fomos explicitando, bem como pela postura pedagógica que enquanto professoras do ensino superior temos assumido, e que assenta em processos de permanente reflexão na e sobre a acção (ZEICHNER, 1993), o recurso ao sistema b-learning foi por nós "agarrado" como mais um desafio profissional. Admitimos também que no "agarrar" deste desafio esteve a convicção pedagógica de considerarmos que a opção por este dispositivo pedagógico se reverte num conjunto de vantagens, de entre as quais a aprendizagem autónoma ocupa posição de destaque. Mas, e como afirmámos, para que tal aconteça é crucial que existam condiçóes iguais, para todos os estudantes, de acessibilidade ao equipamento informático. Esta é, em nosso entender, uma condição determinante no sucesso das experiências desenvolvidas em sistema b-learning, pois a sua náo existência compromete o sentido de participação democrática que lhe é inerente e que defendemos. Deste ponto de vista, estamos a considerar que a não existência de condiçóes de acesso ao equipamento informático constitui uma grande desvantagem e mesmo um problema que pode impedir o recurso a este dispositivo pedagógico-didáctico. 
Ao mesmo tempo, e também como demos conta ao longo deste texto, o professor neste processo ganha outra centralidade por representar um papel configurado numa dupla face: a face presencial e a face virtual. Como argumentámos, a vivência deste papel exige "sair" dos esquemas tradicionais de ser professor e situar-se num paradigma de formação onde a co-responsabilização deve constituir a marca e onde o espaço presencial de sala de aula se cruza com o espaço virtual. Porém, a experiência diz-nos, e os estudos revelam, que a atribuição de centralidade aos estudantes nos processos de ensino-aprendizagem não é um processo fácil nem tão pouco constitui uma regra nos quotidianos institucionais. Na experiência que aqui relatámos também nós lidamos com essa dificuldade. Algum caminho foi percorrido. Sabemos hoje, e o feedback dos estudantes reforça essa visão, que esse caminho construiu alicerces para experiências futuras mais consistentes e sistemáticas.

\section{Notas}

1 Essa declaração foi assinada pelos seguintes países: Áustria, Bélgica (comunidades flamenga e francófona), Bulgária, República Checa, Dinamarca, Estónia, Finlândia, França, Alemanha, Grécia, Hungria, Islândia, Irlanda, Itália, Letónia, Lituânia, Luxemburgo, Malta, Holanda, Noruega, Polónia, Portugal, Roménia, República Eslovaca, Eslovénia, Espanha, Suécia, Suíça e Reino Unido.

2 Lembre-se que a Declaração de Bolonha (BOLONHA, 1999, p. 2) propóe a importância do que designa "Suplemento de Diploma para promover a empregabilidade dos cidadáos europeus e a competitividade interna do sistema de ensino superior europeu".

3 Este decreto-lei clarifica: no capítulo I, os Princípios reguladores de instrumentos para a criação do espaço europeu de ensino superior (Objecto, âmbito e conceitos); no capítulo II, a definição do Sistema de créditos curriculares (expressão, $\mathrm{n}^{\circ}$, Trabalhos de dissertação e de tese, Avaliação, acompanhamento e acreditação, entre outros); no capítulo III, a Avaliação, classificação e qualificação; no capítulo IV, a Mobilidade durante a formação; no capítulo V, a Mobilidade após a formação (Suplemento ao diploma); e no capítulo VI, Disposiçōes finais e transitórias (prazos). 
4 Estamos a referir-nos a processos formais de debate organizados pelas instituiçóes do ensino superior, calendarizados, divulgados e abertos ao público, e a espaços de reflexão de carácter mais informal, gerados no interior das instituiçóes.

5 Também Torres $(2001$, p. 1) considera que o "termo Comunidade de Aprendizagem (CA) foi estendido nos últimos anos, com acepçóes diversas. [...] A diversidade de usos da noçáo de comunidade de aprendizagem (CA) é perpassada por três eixos: a) o eixo escolar/extraescolar, b) o eixo real/virtual e c) o eixo relacionado com a grande gama de objectivos e sentidos atribuídos à CA".

6 Coll (2003), para além desta Comunidade de Aprendizagem (CA) identifica mais três tipos: Comunidades de Aprendizagem em sala de aula. Neste caso, "As Comunidades de Aprendizagem em sala de aula apresentam uma grande variedade, mas a característica mais frequente é que a ênfase não se dá na aprendizagem individual, mas na construção colectiva do conhecimento, no sentido de que o aluno, quando aprende, é porque aprende num processo de construção, de aquisição de capacidade, de conteúdo e actividades colectivo. A ênfase está sempre na aprendizagem do grupo"; Comunidades Escolares de Aprendizagem. A diferença fundamental em relação ao primeiro tipo é que neste caso, a proposta não se dá nos processos de ensino-aprendizagem, mas nos aspectos de organizaçáo curricular e de funcionamento da escola [...]". Confere-se uma grande importância "à reflexão sobre a prática, à articulação teórico-prática, à acção de processos de melhoria das práticas pela utilização de recursos teórico-reflexivos no interior da comunidade as quais reflectem, por sua vez, os níveis de participação e confiança entre os membros do grupo"; Comunidades de Aprendizagem territoriais, definidas como" experiências ligadas a estratégias de desenvolvimento comunitário no âmbito económico baseadas na vocaçáo comunitária”.

7 Segundo Duggleby (2002, p. 42), “as intervençóes do professor online podem ser agrupadas em onze categorias: acolhimento dos alunos; encorajamento e motivação; monitorizaçáo dos progressos do aluno; confirmação dos ritmos de aprendizagem; disponibilização e explicação de informação; feedback sobre os trabalhos dos alunos; avaliação; responsabilização pelo sucesso dos fóruns; construção de uma comunidade de aprendizagem; apoio técnico; e conclusão do curso". 
8 Importa referir que os inquéritos foram respondidos por um grupo de 45 estudantes, de um total de 65 estudantes que frequentaram a unidade curricular Processos de Desenvolvimento do Currículo, do 2o ano da Licenciatura em Ciências da Educação no primeiro semestre do ano lectivo de 2008/2009.

\section{REFERÊNCIAS}

BARDIN, Laurence. A análise de Conteúdo. Lisboa: Edições 70, 1991.

BERNSTEIN, Basil. La estructura del discurso pedagógico. Madrid:

Morata, 1993.

BOLONHA. Declaração de Bolonha, 1999. Disponível em: http://paco. ua.pt/common/bin/Bolonha/Bolonha_Declaracao\%20de\%20Bolonha. pdf. Acesso em: 14 jul. 2010.

COLL César. Comunidades de aprendizagem e educaçáo escolar. Entrevista a César Coll, 2003. Disponível em: <http://www.crmariocovas. sp.gov.br/ent_a.php?t=011>. Acesso em: 14 jul. 2010.

DIAS, Paulo. Da e-moderaçáo à mediaçáo colaborativa nas comunidades de aprendizagem. Educação, Formação \& Tecnologias, Universidade do Minho, v. 1, n. 1, p. 4-10, abril, 2008.

DUGGLEBY, Julia. Como ser um tutor online. Lisboa: Monitor , 2002.

LEITE, Carlinda. Provas de Agregação. Porto: FPCE UP, 2006.

Documento policopiado. Relatório da disciplina Teoria e Fundamentos do Currículo.

LESSARD, Claude. A Universidade e a formação profissional dos docentes: novos questionamentos. Educação \& Sociedade: Revista de Ciências da Educação, Campinas, v. 27, n. 94, p. 223-249, jan./abr. 2006.

MEIRIEU, Philippe. La pédagogie différenciée: l'essenciel en une page. Les cahiers pédagogiques, Paris, n. especial Différencier la pédagogie, p. 75, 1988.

MORAIS, Nídia; CABRITA, Isabel Maria. Ambientes virtuais de aprendizagem: comunicação (as)síncrona e interacção no ensino superior.

PERSPECTIVA, Florianópolis, v. 29, n. 2, 507-533, jul./dez. 2011

http://www.perspectiva.ufsc.br 
Revista de Ciências da Informação e da Comunicação do CETAC, Porto, n. 6, p. 158-179, jul. 2008.

MORAN, José Manuel. Os modelos educacionais na aprendizagem on-line. Disponível em: <http://www.eca.usp.br/prof/moran/modelos. htm>. Acesso em: 15 jul. 2010.

PORTUGAL. Decreto-lei no 42 de 22 de Fevereiro de 2005, DIÁRIO DA REPÚBLICA - I SÉRIE-A no 37. Institui, em coerência com os compromissos resultantes dos desenvolvimentos do Processo de Bolonha, os princípios reguladores dos instrumentos para a criação do espaço europeu de ensino superior.

PORTUGAL. Decreto-Lei no 74, de 24 de Março de 2006. DIÁRIO DA REPÚBLICA-I SÉRIE - A_N.o 60. Procede à regulamentaçấo das alteraçôes introduzidas pela Lei de Bases do Sistema Educativo (Lei no 46 de 14 de Outubro de 1986, revogada pela Lei no 49 de 30 de Agosto de 2005) relativas ao novo modelo de organização do ensino superior no que respeita aos ciclos de estudos, no quadro do Processo de Bolonha.

SALMON, Guly. E-Moderating: the key to teaching and learning online. London: Kogan Page, 2000.

TORRES, Rosa Maria. Comunidade de aprendizagem: a educação em função do desenvolvimento local e da aprendizagem. 2001. Disponível em: <http://www.teresianasstj.net/files/met/Comunidade_de_ Aprendizagem.pdf>. Acesso em: 15 jul. 2010.

VALA, Jorge. A análise de conteúdo. In: SILVA, Augusto S.; PINTO, José Madureira. Metodologias das ciências sociais. Porto: Afrontamento, 1986. p. 101-128.

WENGER, Etienne. Informal learning. In: E-LEARNING LISBOA: Delivering in the Lisbon Agenda, 7, 2007, Lisboa. Anais... Lisboa, 2007.

WITTORSKI, Richard. Da fabricação das competências. In: TOMASI, Antônio (Org.). Da qualificação à competência. Campinas: Papirus, 2004. p. 75-90.

ZEICHNER, Kenneth. A formação reflexiva de professores: ideias e práticas. Lisboa: Educa, 1993. 


\section{Pedagogic innovation: a response to the demands of the university classroom} Abstract

The aim of this paper is to inform about the curricular experience developed in the context of the b-learning system, with students of the 1st year of the Degree in Science Education of Faculty of Psychology and Science Education, University of Porto. In the context of the challenges and the principles laid out by the Bologna Process, the article discusses possibilities and limitations of the use of discussion forums (used in the system b-learning) to develop autonomous learning processes. From the methodological point of view, we used a questionnaire of open questions that aimed to capture the reaction of the students on this pedagogical device. The content analysis followed the procedures of Bardin (1991) and was based on the ideas of Salmon (2000) about the role of the teacher. Overall, the results show that students have great and very positive opinion on the use of discussion forums believing they are an important pedagogical device to enhance its training. Recognize, also, that these forums enhance their accessibility to different materials and allow a better organization of the contents, constituting, by that, a support to their study. We conclude that the choice of this pedagogical device ends up in a set of advantages for students and teachers, between which

\section{Innovación pedagógica: una respuesta a las demandas de las aulas universitarias}

\section{Resumen}

Tenemos la intención de compartir una experiencia desarrollada en el currículo en el sistema b-learning con alumnos de ler año de la Licenciatura en Ciencias de la Educación, Facultad de Psicología y Ciencias de la Educación, Universidad de Oporto. En el contexto de los desafíos y los principios establecidos por el proceso de Bolonia, el artículo analiza las posibilidades y limitaciones del uso de los foros de discusión (utilizado en el sistema b-learning) para desarrollar procesos de aprendizaje autónomo. Desde el punto de vista metodológico, se utilizó un cuestionario de preguntas abiertas que pretendía captar la reacción de los estudiantes en este dispositivo pedagógico. El análisis de contenido seguido los procedimientos de Bardin (1991) y se basó en las ideas de Salmon (2000) sobre el papel del profesor. En general, los resultados muestran que los estudiantes disfrutan de manera muy positiva el uso de los foros de discusión cree que este es un importante dispositivo pedagógico para mejorar su formación. Reconocen también que permitan una mayor accesibilidad a los diferentes materiales y una mejor organización del contenido de lo que constituye también un medio para apoyar el estudio. Llegamos a la conclusión de que la elección de este dispositivo pedagógico se convierte en un conjunto de ventajas 
the autonomous learning occupies a prominent position.

Keywords: B-learning. Discussion forums. Learning. para los estudiantes y profesores, en el cual el aprendizaje autónomo ocupa un lugar destacado.

Palabras claves: B-learning. Foros de discusión. Aprendizaje.

\section{Carlinda Leite}

E-mail: carlinda@fpce.up.pt

\section{Preciosa Fernandes}

E-mail: preciosa@fpce.up.pt

Recebido em: 7/4/2011

Versão final recebida em: 23/10/2011

Aprovado em: 31/10/2011 